DOI: https://doi.org/10.18309/anp.v51iesp.1439

\title{
SAPATOS E RITMOS DOS PASSOS: NOTAS SOBRE "PRECIOSIDADE", DE CLARICE LISPECTOR
}

\section{SHOES AND THE RHYTHM OF THE STEPS: NOTES ON "PRECIOSIDADE", BY CLARICE LISPECTOR}

\author{
Iara Machado Pinheiro \\ Universidade de São Paulo, São Paulo, São Paulo, Brasil \\ pinheiro.m.iara@gmail.com
}

Resumo: Este artigo propõe uma leitura do conto "Preciosidade", de Clarice Lispector e parte da coletânea Laços de Família (1960), se detendo na reincidência dos sapatos como imagens de transições e mediações entre o íntimo e o externo, e com o amparo do ensaio Os sapatos rotos, de Natalia Ginzburg, e de um dos capítulos que formam A amiga genial, de Elena Ferrante. A interpretação seria que os sapatos no conto de Clarice possam ser entendidos como o necessário e doloroso deslocamento da casa como referência única de autoridade e o peso de responsabilidade imbuída na liberdade.

Palavras-chave: Psicanálise; Crítica literária; Clarice Lispector

Abstract: This article proposes an analysis of the short story "Preciosidade", by Clarice Lispector, which is part of the short story collection Laços de Familia (1960). Supported by the essay Le scarpe rotte, by Natalia Ginzburg, and one of the chapters in L'amica geniale, by Elena Ferrante, such interpretation focuses on the recurrence of shoes as images of transition and mediation between the private and the external. In Lispector's story, they may be perceived as the necessary and painful displacement of one's home as the only reference of authority, just as the burden of responsibility that comes along with freedom.

Keywords: Psychoanalysis; Literary criticism; Clarice Lispector 
No ensaio $O$ vertiginoso relance, Gilda de Mello e Souza tece alguns comentários a respeito de $A$ maçã no escuro. Antes de chegar propriamente ao romance de Clarice Lispector, a crítica propõe um certo escopo de olhar comum à escrita feminina: a visão de míope. Privadas por tanto tempo dos espaços públicos, as mulheres teriam desenvolvido a habilidade de notar os detalhes dos espaços internos, de modo que a aparência de insignificância fosse desvelada por um "olhar baixo" responsável por fazer as coisas próximas adquirirem "uma luminosa nitidez de contornos" (SOUZA, 1963, p. 79).

Com as palavras da crítica tento me aproximar do conto "Preciosidade" (1960), também de Clarice, sobretudo porque nessa narrativa o olhar baixo delimita o campo de visão da história: desde o início a condução do narrador leva o olhar do leitor ao chão e o convida a reparar nos movimentos humanos pelos pés e nas coisas pela perspectiva de baixo. $\mathrm{O}$ enredo da menina, redimensionada por um encontro fortuito com estranhos na rua, será lido pela imagem dos sapatos, pelo recorte de visão que eles delimitam e pela maneira que eles figuram na narrativa. Após ser atropelada por uma experiência sem nome, a personagem pede aos pais novos sapatos, uns que não façam barulho. Alguma coisa da vivência inédita faz com que os antigos calçados sejam inadequados para os passos que os pés da menina deveriam seguir dali para frente. Aqui tento pensar sobre a particularidade da compressão do inefável nos sapatos, qual a natureza da metonímia em questão?

\section{Outros sapatos}

O reencontro com o conto de Clarice me levou com olhos diferentes para outros textos sobre sapatos. O primeiro deles é o ensaio Os sapatos rotos (2015), de Natalia Ginzburg, que se detém num momento de indefinição da vida da escritora italiana. Jovem viúva e com três filhos pequenos, ela tenta, aos tropeços, calibrar o ritmo dos passos que seguirá a perda do marido e a destruição de pilares que ordenavam a vida até então. Aqui também o campo de visão é o chão: o texto é todo sobre sapatos, os dela e os da amiga que repousam junto à porta enquanto conversam no quarto de pensão que dividem:

Tenho os sapatos rotos, e a amiga com que vivo neste momento também tem os sapatos rotos. Quando estamos juntas, falamos sempre de sapatos. Se lhe falo do tempo em que serei uma escritora velha e famosa, ela logo me pergunta: "Com que sapatos?". Então lhe digo que terei sapatos de camurça verde, com uma grande fivela de ouro ao lado. (GINZBURG, 2015, p. 20).

No texto, sapatos estão atrelados a jeitos de estar no mundo, falar sobre sapatos, portanto, não é falar de moda. É mesmo outra coisa que está em questão, e as expectativas em relação ao futuro ganham a forma de sapatos radicalmente diferente dos que ela tem nos pés naquele momento. Como a personagem de Clarice, também no texto de Ginzburg, no ambiente interno, é possível andar descalço; os calçados são apresentados como anteparos para mediar o contato com o chão de fora.

A construção do texto contrasta a referência da casa dos pais, onde os pés são resguardados e aquecidos, enquanto os dela, sozinha em Roma, são envolvidos por sapatos rotos - "pertenço a uma família em que todos têm sapatos sólidos e saudáveis. Aliás, minha mãe teve até de fazer um armarinho só para guardar os sapatos, de tantos pares que tinha (...) Mas sei que também se pode viver com sapatos rotos" (GINZBURG, 2015, p. 20). Ginzburg pensa sobre períodos indefinidos da vida com a imagem de alguém que só tem um par de 
sapatos, furados ainda por cima. E não é possível levá-los ao sapateiro porque nesse caso não teria como fazer mais nada.

\begin{abstract}
No período alemão eu estava sozinha aqui, em Roma, e tinha apenas um par de sapatos. Se fosse levá-los ao sapateiro, teria de passar dois ou três dias na cama, e isso não era possível. Assim continuei a usá-los, e para piorar chovia, sentia que eles se desfaziam lentamente, moles e informes, e sentia o frio do piso sob a planta dos pés. É por isso que ainda hoje uso sempre sapatos rotos, porque me lembro daqueles, e então estes não são tão ruins em comparação. (GINZBURG, 2015, p. 20).
\end{abstract}

As memórias são relatadas de forma que contenham mais do que a narração de determinado período da vida. Elas vão sendo articuladas com a relação entre os sapatos que se tem nos pés e a configuração dos passos. A construção do ensaio chega à educação dos filhos e coloca como pergunta quais os possíveis efeitos de se andar com pés desprotegidos logo na infância:

Eu e minha amiga conversamos longamente sobre isso e sobre como vai ser o mundo quando eu for uma velha escritora famosa e ela estiver girando o mundo com uma mochila nas costas, como um velho general chinês, e meus filhos seguirem seu caminho com sapatos sadios e sólidos nos pés e o passo firme de quem não renuncia, ou com sapatos rotos e o passo frouxo de quem sabe o que não é necessário. (GINZBURG, 2015, p. 22).

O texto é concluído com a suposição de que para "aprender mais tarde a caminhar com sapatos rotos talvez seja bom ter os pés enxutos e aquecidos quando se é criança" (GINZBURG, 2015 , p. 23), ou seja, a forma que os pés encontram a rua pela primeira vez terá efeitos na determinação dos passos futuros. A hipótese de que pés aquecidos, ao longo da formação como sujeito, ajudam também a caminhar com calçados furados posteriormente poderia ser entendida como o prolongamento das primeiras experiências na vida futura. Isto é, as reverberações de pertencimento a um lar e das maneiras que o cuidado é investido perduram de tal modo que também serão variáveis para a determinação dos modos que um corpo encontra o mundo.

De Natalia Ginzburg meu percurso pelos sapatos me levou até Elena Ferrante. Em $A$ amiga genial (2015), o capítulo destinado à adolescência se chama História dos sapatos. $\mathrm{O}$ título é amparado pelo enunciado, já que o pai de Lila, uma das protagonistas, é sapateiro e a personagem, altiva e indomável, tenta fazer do ofício do pai uma forma de garantir uma vida diferente para si, isso ambientado em um pós-guerra de reconstrução da Itália, com o reaquecimento do comércio e a maior circulação de mercadorias no bairro periférico de Nápoles, onde a história se passa. A ligação entre os sapatos e a adolescência, junto, portanto, ao delineamento de novos contornos para o corpo, parece digna de cuidado, ainda mais se pensar que o corpo da narradora de Ferrante também passará, nessa história, pela invasão de um homem, encontro com algo sem nome que mistura prazer e repulsa.

No regime diegético de A amiga genial, a História dos sapatos será o momento em que os caminhos das duas amigas protagonistas se bifurcam. No ensaio de Natalia, os sapatos furados aparecem como ilustração de um momento de adversidade e futuro indefinido que relega os pés a continuarem em movimento, ainda que errático, porque não haveria outra opção que não a entrega. $\mathrm{O}$ desvio por essas duas outras representações de olhar baixo que focam o chão permitiria supor algumas hipóteses claudicantes para ler o conto de Clarice: sapatos mediam o contato entre os pés e a rua, entre corpo e mundo, entre privado e público, entre a casa e o fora. Como figuras de mediação, eles poderiam ser lidos como metonímia do que é 
intermediário, como uma transição de algo que começa a se perder sem que o sucessor tenha contornos claros.

Sobre a transição entre casa e rua, O romance familiar do neurótico (2014), de Freud, traz à tona o delicado e necessário deslocamento de autoridade do âmbito familiar para o público: o processo constituinte de subjetivação passaria pela descentralização da família como referência para que outras possam emergir. Não há apagamento, as marcas impressas pelos pais no trato com si mesmo e o ao redor permanecem como, para usar outra imagem de Freud (1976), traços riscados num bloco mágico. Esse brinquedo é formado por uma tela resguardada por uma superfície e contém uma ferramenta para apagar as inscrições. Só que não há apagamento bem acabado e o estilete responsável pelas marcações irá deixar vestígios de incisões na superfície, mesmo que a folha esteja em branco. É com essas marcas que devemos sair de casa e nos deparar com situações cuja cartilha de conduta nenhuma será capaz de amparar completamente.

\section{Os limiares: acordar e sair de dentro}

O conto "Preciosidade" é aberto junto com os olhos da personagem principal. Quando acorda, ainda há um instante de vastidão, possivelmente um resto da indomesticável inconsciência. Em seguida, há o trajeto para o colégio. $\mathrm{O}$ caminho entre a casa e a escola é o espaço predominante da narrativa, é um enredo sobre movimentos. Como os sapatos, o deslocamento também é mediação: é a transição da casa como referência de autoridade para a escola. É o momento, portanto, em que não há olhos de vigilância, é um trecho sem lei clara entre as regras de casa e as da escola.

Ser olhada é outro aspecto prevalente do conto. Em alguns momentos, aliás, o narrador nos convida a encarar o mundo pelos olhos da personagem para relatar o temor de ser vista, notada. A ênfase em não querer ser olhada é reiterada tão intensamente ao ponto de levantar suspeitas. Suspeitas que não precisam passar pelo caminho simplista da negação - querer ser olhada - mas, novamente com Freud, em Repetir, recordar, elaborar (2010), pensar que a reincidência sinaliza a presença de certo teor com forte investimento psíquico, que exerce importância crucial na organização subjetiva da realidade material. A repetição seria correlativa à força das resistências vinculadas a determinado conteúdo (FREUD, 2010), de modo que é importante olhá-la segundo suas articulações, já que, quanto maior a intensidade, mais difícil se aproximar do que provoca a reincidência. No conto, a ênfase nas conjugações do verbo olhar entra em choque com o campo de visão do chão, que privilegia os sapatos. É com esse aparente desencontro que a narrativa se desenrola: o narrador conduz o olhar do leitor ao chão, e a personagem fala frequentemente sobre ser olhada.

A riqueza das ruas que separam a personagem da escola parece ter mais apelo aos olhos da menina pela manhã, impressão que deriva da própria economia da narrativa. A descrição do caminho até escola é minuciosa, tanto o percorrido a pé quanto o que se desenrola no ônibus e no bonde. Ao passo que a volta para a casa é relatada em apenas um parágrafo, iniciado com a pressa que acompanha a fome. Como se houvesse alguma possibilidade de saciar outro tipo de apetite quando anda pelas ruas vazias entre as luzes que separam a madrugada da manhã, enquanto na volta, quando "o cuidado tinha que ser maior, ela era protegida pela espécie de feiura que a fome acentuava, seus traços escurecidos pela adrenalina que escurecia a carne dos animais de caça" (LISPECTOR, 2009, p. 85).

O proveito do caminho dependia de não ser olhada. Ainda que o temor pareça o de ser vista em abstrato, o narrador constrói uma certa gradação dos olhares que seriam mais nocivos: 
"Aqueles homens que não eram mais rapazes. Mas também de rapazes tinha medo, medo também de meninos" (...) Eles olhavam e não a viam; ela fazia mais sombra do que existia" (LISPECTOR, 2009, p. 83). Medo ela tinha de homens, rapazes e meninos, mas, por o medo ser de ser vista, é possível que eles olhem e a não vejam: é um olhar de determinada natureza que desperta o temor.

No Seminário Livro Um - os escritos técnicos de Freud (2009), Lacan propõe um estatuto para o olhar que extrapola o que "se situa simplesmente ao nível dos olhos": "Os olhos podem muito bem não aparecer, estar mascarados. O olhar não é forçosamente a face de nosso semelhante, mas também a janela atrás da qual supomos que ele nos espia. É um x, o objeto diante do qual o sujeito se torna objeto" (LACAN, 2009, p. 286). O fragmento ajuda a entender os olhos que olham e não veem no conto, por dar uma acepção específica ao verbo: trata-se de uma dinâmica que passa pela forma que nós mesmos nos supomos espiados, de um sentido forjado pelo sujeito mas que o relega ao lugar de objeto. De outro modo, quem se sente olhado atribui um escopo para o outro que é ativo na ação, enquanto quem supõe fica passivo à revelia de quem ele imagina como observador. É uma dinâmica correlativa: é o lugar onde nos formamos, mas é construído por nós mesmos e atribuído a uma instância alheia. Na narrativa, o medo que passa dos homens para os rapazes e em seguido para os meninos - como a reincidência do verbo olhar - vai dando notícias ao leitor sobre a forma que a personagem organiza o mundo.

\footnotetext{
Ainda teria que enfrentar na escola o longo corredor onde os colegas estariam de pé conversando, e onde os tacos de seus sapatos faziam um ruído que as pernas tensas não podiam conter como se ela quisesse inutilmente fazer parar de bater um coração, sapatos com dança própria (...) Era feio o ruído se seus sapatos. Rompia o próprio segredo com tacos de madeira. Se o corredor demorasse um pouco mais, ela como que esqueceria seu destino e correria com as mãos tapando os ouvidos. Só tinha sapatos duráveis. Como se fossem os mesmos que em solenidade lhe haviam calçado quando nascera (LISPECTOR, 2009, p. 84).
}

Nessa passagem, a antítese em termos de campo de visão - ser olhada e a prevalência dos sapatos - parece encontrar uma síntese pelo som: os calçados fazem barulho que se mistura à conversa dos colegas no corredor, dinâmica de sociabilidade da qual ela está alheia. Os sapatos denunciam a presença da personagem num ambiente de convívio coletivo, talvez o rompimento do próprio segredo seja o impossível de habitar apenas dentro de si. É uma coação para que ela ceda às demandas alheias e não esteja sozinha com a vastidão vagarosa do próprio desejo.

Também parece haver a marcação de certa insuficiência: ela só tem sapatos duráveis. A oração posterior traça com o recurso da comparação uma continuidade desses calçados com a primeira infância. A durabilidade que caracteriza os sapatos da menina parece oposta aos adornos que revestem os sapatos das mulheres. A contiguidade com o que lhe foi inoculado no nascimento poderia permitir supor que se trata de características infantis em termos de aparência, como se ela não quisesse se apresentar ao mundo com sapatos que apenas têm a serventia de calçar, bem como da persistência de marcas do jeito de existir ensinado em casa, marcas que começam a esboçar um choque com modos de existir que possam ser forjados fora de um olhar de tutela.

Na casa vazia, sozinha com a empregada, já não andava como um soldado, já não precisava tomar cuidado. Mas sentia falta da batalha das ruas. Melancolia da liberdade, com o horizonte ainda tão longe. Dera-se ao horizonte. Mas a nostalgia do 
presente. O aprendizado da paciência, o juramento da espera. Do qual não soubesse jamais se livrar. A tarde transformando-se em interminável e, até todos voltarem para o jantar e ela poder se tornar com alívio uma filha, era o calor, o livro aberto e depois fechado, uma intuição, o calor: sentava-se com a cabeça entre as mãos, desesperada. (LISPECTOR, 2009, p. 86).

Em casa, quando não é preciso da rigidez dos passos de soldado, a "batalha das ruas" faz falta. A insatisfação crônica de quem quer sem saber o que quer faz a liberdade coexistir com a melancolia: ela sente falta de algo que não foi experimentado apenas com deleite. E, dentro dos limites conhecidos, há certo prazer no estado de alerta que não exclui o alívio por poder ser filha quando os pais chegam em casa. Enquanto que a rua, como lugar exclusivo de passagem onde a presença só é permitida caso tenha a finalidade de chegar a algum local, relega a menina a uma espera que alonga o decorrer do tempo. As marcas no bloco mágico junto à ambígua curiosidade de não ser apenas filha parecem gerar um paradoxal esboço de autonomia: toma-se cuidado porque recebe-se essa orientação, em geral dos pais, mas quando se é soldado, não se é filha, é ela quem deve zelar por si. Diferente da casa e da escola, na rua ninguém, que não seja a própria personagem, é responsável por ela mesma.

\section{O tropeço e o meio do caminho}

A cena do encontro com os rapazes também oscila entre olhos e pés, entre notar a presença de quem ela não contaria que estivesse lá e o sons da proximidade e do distanciamento posterior: "com os olhos franzidos pela incredulidade no fim longínquo de sua rua, de dentro do vapor, viu dois homens. Dois rapazes vindo. Olhou ao redor como se pudesse ter errado de rua ou de cidade. Mas errara os minutos: saíra de casa antes que a estrela e os homens tivessem tempo de sumir" (LISPECTOR, 2009, p. 87). A situação se esboça para a personagem de tal modo que não há retorno: refazer os passos não afastaria os olhos deles. Ela não sabe o que fazer e, fora de casa e da escola, não há mais ninguém para dizer como proceder, ou, nas palavras do narrador, "arriscara-se a ser um ela-mesmo que a tradição não amparava" (LISPECTOR, 2009, p.89).

De pernas heroicas, continuou a andar. Cada vez que se aproximava, eles que também se aproximavam - então todos se aproximavam, a rua ficou cada vez um pouco mais curta. Os sapatos dos dois rapazes misturavam-se ao ruído de seus próprios sapatos, era ruim de ouvir. Era insistente ouvir. Os sapatos eram ocos ou a calçada era oca. A pedra do chão avisava. Tudo era eco e ela ouvia, sem poder impedir, o silêncio do cerco comunicando-se pelas ruas do bairro, e via, sem poder impedir, que as portas mais fechadas haviam ficado. Mesmo a estrela retirara-se. Na nova palidez da escuridão, a rua entregue aos três. Ela andava, ouvia os homens, já que não poderia olhá-los e já que precisava sabê-los. Ela os ouvia e surpreendia-se com a própria coragem em continuar. Mas não era coragem. Era o dom. E a grande vocação para um destino. Ela avançava, sofrendo em obedecer. Se conseguisse pensar em outra coisa não ouviria os sapatos. Nem o que eles pudessem dizer. Nem o silêncio com que cruzariam. (LISPECTOR, 2009, p. 88).

Todo o acontecimento é relatado com imagens de míope, com olhar baixo: "Não correu porque seria como errar todos os passos"; "ficou de pé, ouvindo com tranquila loucura os sapatos deles em fuga"; "a calçada era oca ou os sapatos eram ocos ou ela própria era oca. No oco dos sapatos deles ouvia atenta o medo dos dois"; "sem saber com que enchera o tempo, senão com passos e passos, chegou à escola com mais de duas horas de atraso" (LISPECTOR, 
2009, p. 87-89). Não há nome para a situação, não há como chamá-la de abuso porque não tem esse sentido para a personagem. Foi uma confusão de passos, algo sucedido entre os ambientes conhecidos, entre as palavras que ela tinha à disposição.

Quando chega ao colégio, esse meio do caminho a leva a desrespeitar a autoridade escolar para se permitir ficar só e gritar, gritar que ela estava sozinha no mundo. Em casa, novamente sob as leis dos pais, um novo estouro: "Preciso de sapatos novos! os meus fazem muito barulho, uma mulher não pode andar com salto de madeira, chama muita atenção! Ninguém me dá nada! Ninguém me dá nada!” (LISPECTOR,2009, p. 93). Os sapatos novos são encadeados com ser mulher e um nexo pouco claro liga os sapatos que tem com o "ninguém me dá nada". Os pais, confrontados com a emergência do balbucio, se referem a ela como mulher na negação. Antes da narrativa ser encerrada com a sintética frase "então ela ganhou sapatos novos", encontramos a enigmática afirmação: "Uma obscura lei que faz com que se proteja o ovo até que nasça o pinto" (LISPECTOR, 2009, p. 93). Para o pinto nascer, a casca do ovo se rompe. A proteção, portanto, culmina com a quebra do que era fruto de zelo e cuidado.

Quando a menina reivindica novos sapatos para seus pais, ela fala que "uma mulher não pode andar com saltos de madeira". Parece ser a compressão da experiência em uma solicitação endereçada aos pais, talvez como forma possível de relatar o que lhe aconteceu. Ainda que do outro ouça que ela não é mulher, a palavra parece sobretudo comunicar que depois daquela manhã, menina ela não é mais. A sensação de solidão por não ter palavra para contar o que lhe tomou e por sentir o peso de ser responsável por si mesma parecem reforçar a urgência para ser alguma coisa que não o meio do caminho.

Não há um complemento na oração de desfecho que permita ao leitor saber se foram os pais que lhe deram os sapatos novos. E ter a demanda atendida, nesse caso, parece quase uma questão menor. Assim como a psicanálise percebe o sintoma como o deslocamento de um afeto que não pôde encontrar representação, a reivindicação por sapatos novos também não parece agir no cerne da sensação de solidão que tomou a garota depois da experiência na rua. É nesse sentido que proponho a leitura dos sapatos como metonímia, a compressão de algo que, diferente da imagem dos sapatos, não teria como vir à luz.

E o que os sapatos comprimem? Tangenciaria a resposta com outra narradora de Clarice. G.H. (LISPECTOR, 1998) escreve que "somos livres e o inferno é este", isto é, ser unicamente responsável pela própria existência, a despeito de ser um direito civil, é também um fardo, e cabe a cada um constituir um sentido para essa responsabilidade. Volto com $O$ romance familiar do neurótico para tentar concluir que, junto com a ampliação de limites da descentralização da autoridade familiar, advém também um certo desamparo por se ver sem ter a quem recorrer. E a reincidência dos sapatos como imagens para caracterizar passos por conta própria e a adolescência talvez possa ser entendida como parte de ser terrivelmente responsável por si mesmo, como Ginzburg define a vida adulta no ensaio As relações humanas (2015). Sapatos, então, como a frágil proteção que podemos forjar para nós mesmos a fim de encaramos o que as ruas têm de esburacado e desconhecido.

"Transpõe as coisas de seu mundo para uma ordem que lhe agrada" (FREUD, 2014, p. 80): a separação da realidade parte do brincar que Freud comenta em O poeta e o fantasiar (2014) ajuda no desenlace final desse comentário sobre calçados. O conto parece narrar também um sair de si, de dentro da ordem afável e digna de controle por parte do eu, como é o fantasiar, para atender à necessidade de renúncia exigida pela concretude das demandas do outro; é o que os dois rapazes obrigaram a menina a fazer. E para sair de dentro de si é melhor estar calçado, 
nem que os sapatos estejam furados, como os de Ginzburg, para que resquícios dessa ordem agradável persistam mesmo na aridez da realidade material.

\section{Agradecimentos}

O presente trabalho foi realizado com apoio da Fundação de Amparo à Pesquisa do Estado de São Paulo (FAPESP/Brasil); IMP é bolsista de doutorado da FAPESP.

\section{Referências}

FERRANTE, E. A amiga genial. Tradução de Maurício Santana Dias. São Paulo: Biblioteca Azul, 2015.

FREUD, S. (1908). O poeta e o fantasiar. In: FREUD, S. Escritos sobre literatura. Tradução de Saulo Krieger. São Paulo: Hedra, 2014.

FREUD, S. (1909) O romance familiar do neurótico. In: FREUD, S. Escritos sobre

literatura. Tradução de Saulo Krieger. São Paulo: Hedra, 2014.

FREUD, S. (1914) Recordar, repetir e elaborar. Tradução de Paulo César de Souza. In: FREUD, S. Obras Completas, v. 10. São Paulo: Companhia das letras, 2010.

FREUD, S. (1925) O Bloco mágico. In: FREUD, S. Edição Standard Brasileira das Obras Psicológicas Completas de Sigmund Freud V. XIX. Rio de Janeiro: Imago, 1976.

GINZBURG, N. As pequenas virtudes. Tradução de Maurício Santana Dias. São Paulo: Cosac Naify, 2015.

LACAN, J. (1953/54) O Seminário, Livro 1 - Os escritos técnicos de Freud. Tradução de Betty Milan. Rio de Janeiro: Jorge Zahar Editor, 2009.

LISPECTOR, C. Preciosidade. In: LISPECTOR, C. Laços de Família. Rio de Janeiro: Rocco, 2009.

LISPECTOR, C. A paixão segunda G.H. Rio de Janeiro: Rocco, 1998.

SOUZA, G. M. (1963) O vertiginoso relance. In: SOUZA, G. M. Exercícios de leitura. São Paulo: Editora Duas Cidades, 1980.

Recebido em: 15 de outubro de 2020 Aceito em: 10 de novembro de 2020

Publicado em Dezembro de 2020 